\title{
Design and analysis of thermally actuated flaps with em- bedded shape memory alloys
}

\author{
Chi Yang ${ }^{1 *}$, Sylvester Abanteriba ${ }^{2}$, Neng Zhang ${ }^{3}$, Andrew Becker ${ }^{4}$ \\ 1, 2, 3 Department of Engineering, RMIT University, Melbourne, Australia \\ ${ }^{4}$ Defence Science \& Technology Organisation, Melbourne, Australia
}

\author{
Keywords \\ Filtration system \\ Shape memory alloy \\ Splash lubricated gearbox \\ Finite element analysis \\ Lubrication
}

Received: 7 August 2018 Accepted: 4 September 2018 Published: 2 October 2018

\begin{abstract}
In this paper, a new passive filtration system that utilises gravitational force for unfiltered splash lubricated gearbox is presented and analyzed. This filtration system is based on the combination of different types of Shape Memory alloy (SMA) for the controlling of filtration layers' deflection under different conditions. The primary SMA wires are biased by a bending force created by another type of SMA wires that exhibit super-elastic behavior. These wires are embedded in a silicone rubber film. The phase transformation of SMA wires is induced by the change of lubricant temperature. Finite element model based on ABAQUS is developed to simulate the thermo-mechanical behaviors of the filtration layers. A prototype passive filtration system is made. The experimental observations on the thermo-mechanical behaviors of the prototype are shown to be in a good agreement with the numerical simulation results. This shows the capability of the numerical model for estimating the mechanical behavior of filtration layers with embedded SMA wires at different temperatures.
\end{abstract}

(C) 2018 The Author(s). Published by TAF Publishing.

\section{INTRODUCTION}

Splash lubricated gearboxes are widely used in engineering applications, such as truck's main gearbox and helicopter's tail rotor gearbox [1]. However, most splash lubricated gearboxes have not been fitted with filtration systems. Wear debris and environmental ingress generated during operating will continuously contaminate lubricant and causing more severe damages to contacting surfaces inside the gearboxes [2,3]. Conventional unfiltered splash lubricated gearbox's components are made robust enough to against wear. Nowadays, the need for light weight design, a higher requirement of fuel efficiency and reliability has generated an interest in the development of a light weight filtration system for splash lubricated gearboxes.

A passive filtration system that utilises gravitational force to trap wear debris suspended in lubricant has been designed. SMAs with the ability to regain their original shape with external stimuli (e.g., thermal, magnetic, electrical) are used as the actuator to control the opening and closing of the fil- tration system. Comparing to the conventional force-feed filtration system, the passive filtration system does not require pumps and pipes, the whole system consists of several filtration layers that made of two types of shape memory alloys and filtration media (silicone) and a metal frame that mounts the filtration layers above the bottom of lubricant oil sump. When the gearbox is not operating, wear debris and environmental ingress suspended in the lubricant start to settle to the bottom of the oil sump due to gravity. With the decreasing of oil temperature, flap layers are opened due to the bending force created by superelastic SMAs. This allows wear debris and environmental ingress to travel through the filtration frame. Before the gearbox starts to operate in the next time, electrical currently will be applied to SMAs exhibit shape memory effects to activate phase transformation and creates a larger actuation force than the bending force created by superelastic wires, and thus closing the flaps to prevent already settled wear debris and environmental ingress to re-enter contacting sur-

\footnotetext{
${ }^{*}$ Corresponding author: Chi Yang

†email: chi.yang@student.rmit.edu.au
} 
faces of gears and bearings in inside the gearbox. The design of the flap layers needs to consider the forces generated by two different types of SMAs. The influences of the use of different wire diameters on the actuation force generated by shape memory SMAs and recovery force generated by superelastic SMAs need to be studied. Only when the suitable diameters of the wires are used, the controlling of filtration layers' deflection under different conditions can be achieved. The following Figure 1 shows the schematic and cross-section view of an individual filtration frame and a flap layer with embedded SMAs wires.

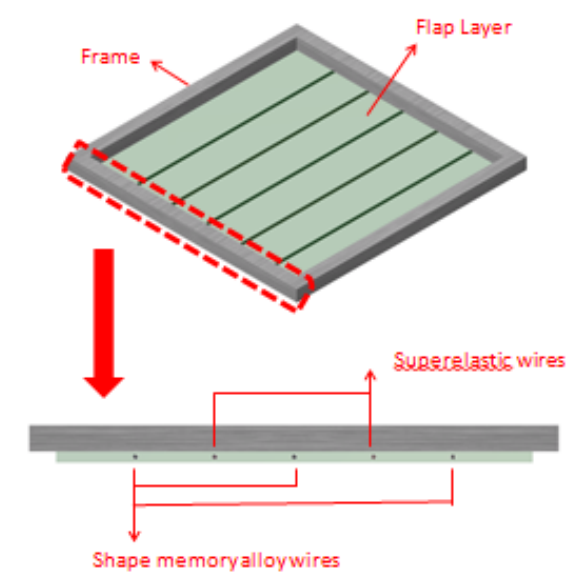

Fig. 1. Schematic of filtration frame and flap layer

The opening and closing of the flap layers are controlled by the change of lubricant temperature. In this paper, the working environment of a helicopter's tail rotor gearboxes has been taken as a sample to be analyzed. The tail rotor gearboxes used on helicopters are unfiltered and splash lubricated. The sizes of wear debris and environmental ingress vary from 1 micrometer to 1 millimeter $[4,5]$. It is found that after the helicopter has landed on the ground for a few hours, most of the wear particles suspended in lubricant tend to settle to the bottom of the oil sump. Lubricant temperature will also gradually decrease to the ambient temperature [6]. At room temperature, the SMA wires with shape memory effects are in martensite phase and they are relatively softer than the superelastic SMA wires. The superelastic wires created a radial bending force toward the bottom of oil sump and forced the flap layer to open. Before the helicopter starts to operate, the shape memory wires are heated with an electric current. Then these wires are changed from their martensite phase to austenite phase, large actuation forces (greater than the bending force created by superelastic wires) will be created during this process.
The original shape of SMA wires with shape memory effects have been set as straight wires. When shape memory wires' phase is changing from martensite to austenite, they will create large bending forces opposite to the bottom of oil sump and force the flap layers to close and stop already settled debris to re-enter gearboxes' contacting surfaces. The normal working temperature of helicopter's tail rotor gearbox is $100^{\circ} \mathrm{C}$, when the lubricant's temperature is above SMA wires' austenite phase transformation temperature (At around $55^{\circ} \mathrm{C}$ ), the electric current can be stopped.

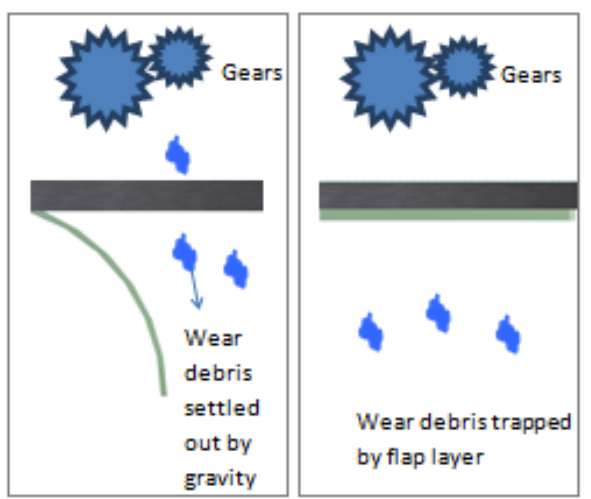

Fig. 2. Flap layer in opening condition (left) and closing condition (right)

The Above Figure 2 shows both the opening and closing conditions of flap layers and the idealized wear debris' location under these two circumstances.

\section{SMA}

The material properties of SMAs may change at different temperatures and applied stresses. There are two unique properties of SMAs; one is pseudoelasticity (also known as superelasticity), which enables SMAs to have a reversible elastic response to large applied forces. The other property shape memory effect allows SMAs to return to their original shape after deformation when heated [7]. The shape memory effect is a result of a thermo-elastic crystalline phase transformation between high temperature phase (Austenite phase) and low temperature phase (Martensite phase). Typically, shape memory alloys can exist in two different phases: high temperature austenite phase and low temperature martensite phase. The martensite phase has two variants based on their different crystal structures, which are twinned martensite and detwinned martensite. The detwinned martensite is a result of changes in twinned martensite's microstructure due to applied mechanical stress [8].

The principles of the shape memory effect and a sample loading path have been shown in the stress-strain- 
temperature diagram in Figure 3. In the beginning of the loading path (starting from the center of the coordinate system at location 1) the SMA is in its twinned martensitic phase. After force is applied, the crystal structure of martensite changes from twinned to detwinned configurations at point 2 . From location 2 to location 3 , load is removed, the deformation and the detwinned martensite crystal structure still remains. Increasing the temperature above austenite phase transformation temperature leads to the phase transformation from martensite to austenite, the original shape of SMA before deformation will also be recovered during this process due to the change in crystal structure. When temperature drops below the martensite phase transformation temperature, SMA will be transformed to martensite phase which stables at low temperature.

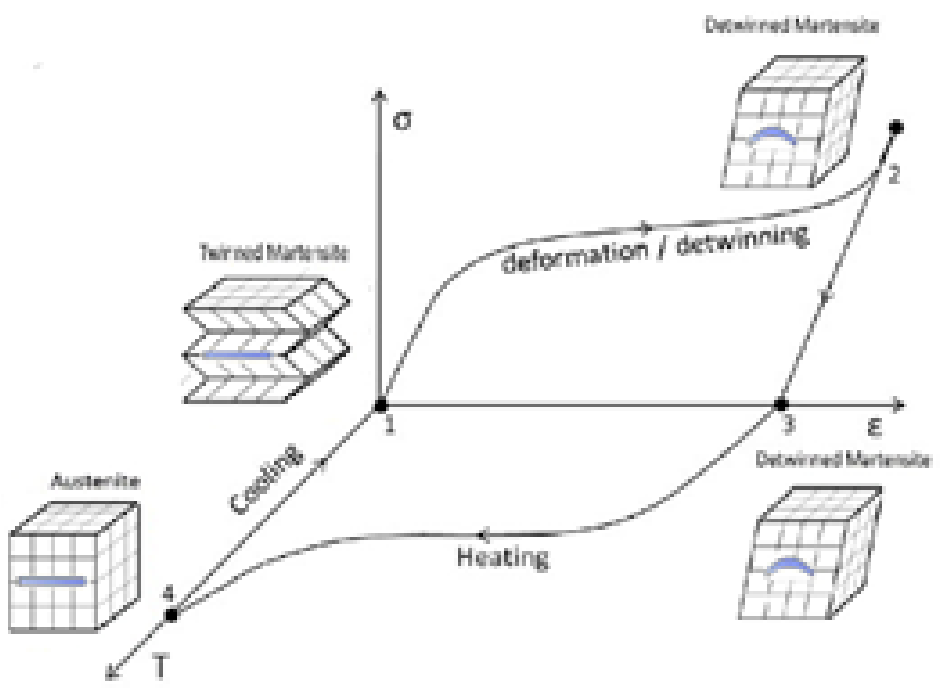

Fig. 3. Schematic of a stress-strain-temperature curve showing the shape memory effect [9]

\section{PASSIVE FILTRATION SYSTEM'S PRINCIPLE}

There are two different types of SMAs used in the filtration layer. The first type of SMAs exhibits shape memory effect; this type of SMAs has the ability to recover its original shape after deformation with external thermal stimuli. The other type of SMAs is superelastic shape memory alloy, this SMAs has high elastic response to large external force. When the external temperature has increased above the
SMAs' Austenite phase transformation temperature, shape memory wires will produce an actuation force to deform the flap layers and regain the shape memory wires' original shape. The shape memory wires have been preset a shape, after activating their phase transformation; the shape memory wires will bend to straight position and thus closing the flaps.

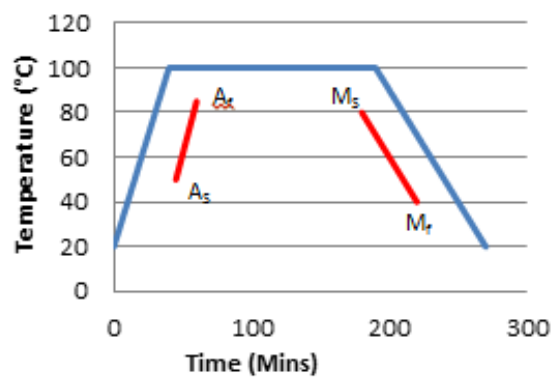

Fig. 4. Thermal cycle of SMA wires. Temperature of lubricant (blue line), phase transformation process of SMA wires (red line) 
The above Figure 4 shows the working principle of SMA wires with shape memory effects in inside a helicopter splash lubricated tail rotor gearbox. The temperature of lubricant inside the gearbox of a complete flight cycle (from takeoff to landing until the next start up) is recorded and shown in above Figure 4 (blue line). The working temperature of the lubricant in helicopter's tail rotor gearbox is about $100^{\circ} \mathrm{C}$.

In the beginning before takeoff, the oil temperature is at near room temperature, with a longer operating time, due to friction of internal components, lubricant's temperature will increase to a steady level of about $100^{\circ} \mathrm{C}$. The SMA wires with shape memory effects used in the flap layer have an austenite phase transformation temperature of $55^{\circ} \mathrm{C}$. Before the starting of gearbox, electric current is introduced to induce phase transformation of shape memory wires. This allows the flap layers to return to their original position. The closed flap layers will also stop wear particles from following the oil flow created by rotating gears to reenter the contacting surfaces inside the gearbox. With the increasing of lubricant temperature during flight process, when lubricant temperature is over shape memory wires' austenite phase transformation temperature (Austenite finish temperature, where $100 \%$ of the wires are transformed from martensite to austenite), the electric current can be stopped. The lubricant's temperature will keep SMA wires to maintain their austenite phase and keeping the flap layers in the closing condition. After landing on the ground, lubricant temperature starts to drop because there is no frictional heating been generated. Eventually, the lubricant temperature will decrease to the same level as the ambient temperature. During this process, the SMA wire will be transformed from austenite phase to martensite phase (starting from $80^{\circ} \mathrm{C}$ and fully completely when temperature reaches $40^{\circ} \mathrm{C}$ ). The downward bending force created by superelastic SMA wires will outweigh the actuation force created by shape memory wires and deforming flap layers to open position. This allows wear debris and environmental ingress to travel through the filtration frame.

\section{EXPERIMENT AND SIMULATION}

Both superelastic wires and shape memory wires received heat treatment to set their original shapes. The following Figure 5 shows the shapes set for these two types of wires. The shape of superelastic wires has been set with an initial angle of $\pi / 2$ radians. The shape memory wires' shape is set as straight wires. After shape setting, the shape memory wires are deformed to the same shape as the superelastic wires, then putting into the mould together with silicone to make the flap layers. In the experiment, the diameter of the superelastic wire is $0.66 \mathrm{~mm}$, and the diameter of the shape memory wire is $0.5 \mathrm{~mm}$.
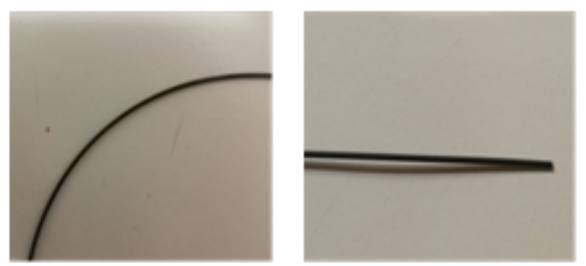

Fig. 5. Shape set for superelastic wires (left), Shape set for shape memory wires (right)

TABLE 1

PROPERTIES OF SHAPE MEMORY WIRE [10]

\begin{tabular}{lll}
\hline \hline Shape Memory Wires & & \\
\hline Young's Modulus & $\begin{array}{l}\text { Austenite } \\
\text { Martensite }\end{array}$ & $83 \mathrm{GPa}$ \\
& $\begin{array}{l}\text { Austenite } \\
\text { Yield strength }\end{array}$ & 195 to $690 \mathrm{MPa}$ \\
& Martensite & 70 to $140 \mathrm{MPa}$ \\
Density & & $6.45 \mathrm{~g} / \mathrm{cm}^{3}$ \\
Specific Heat & & $0.20 \mathrm{cal} / \mathrm{g} * \mathrm{deg} . \mathrm{C}$ \\
Elongation at Failure & & $5-10 \%$ \\
Poisson's Ratio & & 0.33 \\
\hline \hline
\end{tabular}

The properties of the shape memory wires are listed in Table 1. In simulation, model developed by [11] and [12] was used to analyze the deformation of flap layers after the shape memory wires have changed to austenite phase. The simulation results are shown in figure 6, comparing to experimental results in Figure 7. The simulation shows a similar general trend of the flap layer's deformation when shape memory wires are changing from martensite phase to austenite phase at high temperature. However, due to the limited accuracy of the mould to assemble flap layers, shape memory wires and superelastic wires are not always located in the center of silicone filtration media. This causes uniformly distributed stress inside the media and making the flap layers unable to fill gaps on the frame properly.

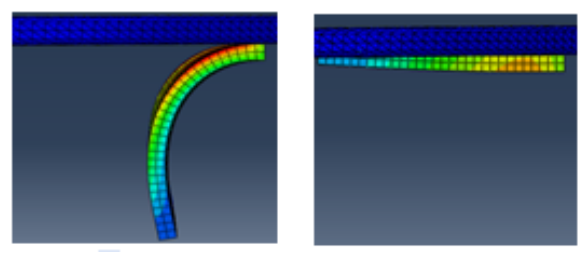

Fig. 6. The flap layer at low temperature open state (left) and at high temperature close state (right) in the simulation 

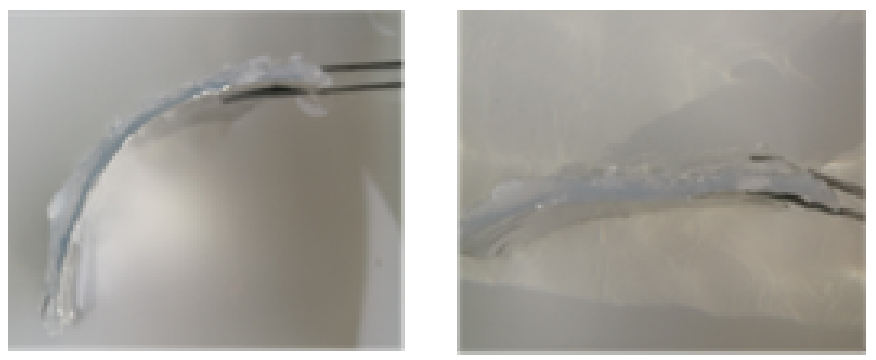

Fig. 7. The flap layer at low temperature open state (left) and at high temperature close state (right) during the experiment

Figure 7 shows the comparison of a flap layer's positions in the experiment at different temperatures. At high temperature at about $100^{\circ} \mathrm{C}$, the shape memory wires are in relative harder austenite phase.

Shape memory wires create larger upward bending forces than the superelastic wire and bending flap layer upwards. This this time, the flap layer is in straight position. When temperature decreases to $20^{\circ} \mathrm{C}$, the flap layer is observed to be bent into an arc, which has the same $\pi / 2$ radians angle as the initial shape of superelastic wires.

\section{CONCLUSION}

In conclusion, the results validate the passive filtration system's principle of combining two different types of shape memory alloys to produce gravitational filtration layers.
The implementation of a filtration system to splash lubricated gearboxes can rarely be found in modern machinery, this design is an attempt to introduce light weight filtration system to increase the cleanliness of lubricant in splash lubricated gearboxes effectively. With cleaner operating, it is expected that the L10 life of gearbox components can be improved considerably.

\section{NOTATION}

The following symbols are used in this paper: Af = austenite finish temperature

As = austenite start temperature

$\mathrm{Mf}=$ martensite finish temperature

Ms = martensite start temperature

\section{REFERENCES}

[1] R. Wiesner, "Structure for cooling helicopter tail rotor gearbox," 1976, US Patent 3,966,145.

[2] A. Becker, S. Abanteriba, and D. Forrester, "Determining inductive sensor wear debris limits for rolling contact fatigue of bearings," Journal of Engineering Tribology, vol. 229, no. 6, pp. 698-711, 2015. doi: https://doi.org/10.1177/ 1350650114559997

[3] H. Seungho, K. Kyehyun, Y. Jaehyun, and K. Jiyeon, “A study on the development of priority estimation process for supporting damage investigation," International Journal of Technology and Engineering Studies, vol. 3, no. 3, pp. 101-110, 2017. doi: https://doi.org/10.20469/ijtes.3.40002-3

[4] A. Becker, S. Abanteriba, S. Dutton, D. Forrester, and G. Rowlinson, “On the impact of fine filtration on spectrometric oil analysis and inductive wear debris sensors," Journal of Engineering Tribology, vol. 230, no. 1, pp. 78-85, 2016. doi: https://doi.org/10.1177/1350650115592917

[5] C. L. S. Tablatin, F. F. Patacsil, and P. V. Cenas, "Design and development of an information technology fundamentals multimedia courseware for dynamic learning environment," Journal of Advances in Technology and Engineering Studies, vol. 2, no. 5, pp. 202-210, 2016. doi: https://doi.org/10.20474/jater-2.6.5

[6] C. Cang, "Design, modelling and analysis of a novel passive filtration system for splash lubricated gearboxes," Journal of Engineering Tribology, vol. 4, no. 5, pp. 23-40, 2019.

[7] H. Kim, Y. Ikehara, J. Kim, H. Hosoda, and S. Miyazaki, “Martensitic transformation, shape memory effect and superelasticity of Ti-Nb binary alloys," Acta Materialia, vol. 54, no. 9, pp. 2419-2429, 2006. doi: https://doi.org/10.1016/j. actamat.2006.01.019

[8] D. C. Lagoudas, Shape Memory Alloys: Modeling and Engineering Applications. New York, NY: Springer, 2008.

[9] M. Follador, M. Cianchetti, A. Arienti, and C. Laschi, “A general method for the design and fabrication of shape memory alloy active spring actuators," Smart Materials and Structures, vol. 21, no. 11, pp. 115-129, 2012. doi: https://doi.org/ 10.1088/0964-1726/21/11/115029 
[10] R. DesRoches, J. McCormick, and M. Delemont, "Cyclic properties of superelastic shape memory alloy wires and bars," Journal of Structural Engineering, vol. 130, no. 1, pp. 38-46, 2004. doi: https://doi.org/10.1061/(asce) 0733-9445(2004)130:1(38)

[11] F. Auricchio, R. L. Taylor, and J. Lubliner, "Shape-memory alloys: Macromodelling and numerical simulations of the superelastic behavior," Computer Methods in Applied Mechanics and Engineering, vol. 146, no. 3-4, pp. 281-312, 1997. doi: https://doi.org/10.1016/s0045-7825(96)01232-7

[12] N. Rebelo, N. Walker, and H. Foadian, "Simulation of implantable nitinol stents," in Abaqus User's Conference, New York, NY, 2001. 